\title{
The Effect of Iron on Cognitive Development and Function in Infants, Children and Adolescents: A Systematic Review
}

\author{
Maria Hermoso ${ }^{a}$ Vesna Vucic ${ }^{b}$ Christiane Vollhardt ${ }^{a} \quad$ Aleksandra Arsic $^{b}$ \\ Blanca Roman-Viñas ${ }^{c}$ Iris Iglesia-Altaba ${ }^{d}$ Mirjana Gurinovic ${ }^{b}$ \\ Berthold Koletzko a \\ ${ }^{a}$ Division of Metabolic and Nutritional Medicine. Dr. von Hauner Children's Hospital, Ludwig Maximilians University \\ of Munich Medical Centre, Munich, Germany; ${ }^{b}$ Centre of Research Excellence in Nutrition and Metabolism, \\ Institute for Medical Research, University of Belgrade, Belgrade, Serbia; ' Community Nutrition Research Centre \\ of the Nutrition Research Foundation, Barcelona Science Park, University of Barcelona, Barcelona, and \\ dGrowth, Exercise, Nutrition and Development Research Group, Escuela Universitaria de Ciencias de la Salud, \\ Universidad de Zaragoza, Zaragoza, Spain
}

\section{Key Words}

Iron requirements $\cdot$ Cognition $\cdot$ Infants $\cdot$ Children $\cdot$

Adolescents · EURRECA

\begin{abstract}
A systematic review was conducted to summarize the evidence currently available from randomized controlled trials (RCTs) concerning the effect of iron intake of infants, children and adolescents on measures of cognitive development and function. The Cochrane Library, MEDLINE and Embase were searched up to and including February 2010. Studies were also identified by checking the bibliographies of the articles retrieved. All RCTs with an adequate control group in which iron supply was provided by natural food sources, fortified foods, formula or supplements to infants, children or adolescents until the age of 18 years were considered for inclusion. No language restrictions were applied. Fourteen studies met the selection criteria. Twelve out of these 14 studies had a high or moderate risk of bias. A large degree of heterogeneity of study populations, iron dosages and outcome measures precluded performing a quantitative meta-analysis. Overall, the studies suggest a modest positive effect of iron
\end{abstract}

supplementation on cognition and psychomotor outcomes in anemic infants and children after supplementation periods of at least 2 months of duration.

Copyright $\odot 2011$ S. Karger AG, Basel

\section{Introduction}

During the first year of life, the body iron content increases markedly. In healthy term infants, iron stores at birth comprise most of the iron requirements for the first 4-6 months. From the 4th month, the requirement for dietary iron increases to an estimated $0.78 \mathrm{mg} /$ day due to the stepwise depletion of endogenous stores and rapid growth with an expansion of blood volume and increased tissue and storage iron [1]. Rapid growth with high iron needs makes infants and young children a particular risk group for iron deficiency anemia (IDA), especially those aged 6-24 months [2]. Adolescents are another risk group for the development of IDA because of rapid growth and increased iron demands during puberty. This is particularly true for adolescent girls due to menstrual losses $[3,4]$. In addition to inadequate intake, factors which

\section{KARGER}

Fax +4161306 1234 E-Mail karger@karger.ch www.karger.com
(C) 2011 S. Karger AG, Basel

0250-6807/11/0594-0154\$38.00/0

Accessible online at:

www.karger.com/anm
Maria Hermoso

Division of Metabolic and Nutritional Medicine, Dr. von Hauner Children's Hospital

Ludwig Maximilians University of Munich Medical Centre

Lindwurmstrasse 4, DE-80337 Munich (Germany)

Tel. +498951 602 832,E-Mail maria.hermoso@med.uni-muenchen.de 
could influence iron status include strenuous exercise, pregnancy, low socioeconomic status and ethnicity, as well as disease-induced malabsorption and chronic blood loss [5] or polymenorrhea in girls [6, 7]. Prevalence estimates of iron deficiency (ID) in adolescent girls range from 9 to $40 \%$, depending on the population studied and the criteria used to define ID [8]. In children below 4 years of age, the estimated prevalence of ID ranges from $20 \%$ in industrialized countries to $39 \%$ in nonindustrialized countries [9]. Anemia is considered to be a public health problem when the prevalence of low hemoglobin concentrations exceeds $5 \%$ in the population. The severity of the public health problem of anemia is classified according to the prevalence of anemia in the population as mild (5.0$19.9 \%)$, moderate $(20.0-39.9 \%)$ or severe $(\geq 40 \%)$ [10]. Worldwide, the estimated prevalence of IDA among preschool-aged children is $25 \%$; among school children it is $40 \%$, and among adolescents it is $30-55 \%$ [11]. The prevalence of ID and IDA in infants is difficult to assess. This is because rapid physiological changes in iron status occur during infancy, and there is no agreement on cut-off values of iron status indicators for ID and IDA.

ID and IDA can have a serious impact on infants' and children's health and later development, i.e. alteration of the immune status, adverse effects on morbidity, delayed behavioral and mental development, below average school achievements and growth retardation, as well as adverse effects on cognition that may or may not be reversible with iron treatment $[8,12]$. Although various studies have been performed using neurodevelopmental outcomes to assess iron requirements in infancy and childhood, results have been inconclusive. Different populations have been studied at different ages with different developmental tests, which makes it difficult to compare the studies [13]. Particular interest in preschool and school children has been shown. Most observational studies in children have found a significant association between IDA and poor cognitive and motor development $[14,15]$, showing that IDA is associated with lower scores on testing of intelligence quotients (IQs). Children 9-11 years old with IDA obtained significantly lower scores on a standardized educational achievement test than did iron-replete children [16]. However, it is not clear whether the ID causes the delay or merely whether the two findings are associated evidence of an underprivileged environment. It is also possible that an early neurodevelopmental insult caused by IDA may not result in detectable psychomotor delay during infancy, but symptoms such as deficits in attention and school performance appear later in older children, young adolescents and adults [13]. In the longest follow-up study to date, in Costa Rica, children identified at 12-23 months who had been treated for severe, chronic ID in infancy still showed differences associated with IDA at the age of 19 years as compared to peers who had good iron status during infancy [15].

There is increasing evidence that low iron status adversely influences physiological functions not only due to reduced hemoglobin synthesis but also because of decreased activity of iron-containing enzymes in the brain [17]. Since in ID, iron appears to be preferentially channelled to hemoglobin synthesis, the brain may become iron depleted when intake is insufficient even if the individual is not yet anemic [17]. A number of animal studies show that ID changes the myelination of neurones, neurometabolism, neurotransmitters and gene/protein profiles before and after iron repletion at weaning [18]. Rodent studies show effects of ID during gestation and lactation that persist into adulthood despite restoration of iron status at weaning [18]. A lack of sufficient iron intake may significantly delay the development of the central nervous system as a result of alterations in morphology, neurochemistry and bioenergetics [19].

The role that iron plays in the neurodevelopment of anemic and nonanemic iron-deficient (NAID) infants, children and adolescents is not fully understood. An effect of iron treatment on cognition was not observed in most trials of children $<2$ years of age with IDA, but it was observed in older children. In children $>2$ years of age and in adolescents with IDA, evidence suggests beneficial effects of iron treatment on cognitive or behavioral function; however, the insufficient number of studies, often associated with different confounders, prevents a thorough assessment.

The European Micronutrient Recommendations Aligned (EURRECA) Network of Excellence attempts to consolidate the basis for the definition of micronutrient requirements across Europe, taking into account relationships among intake, status and health outcomes [20]. Systematic reviews are being conducted on those micronutrients that are deemed to be of major importance for certain population groups, following a standardized methodology. This paper aims to review data from all available randomized controlled trials (RCTs) which met EURRECA's quality standards, to ascertain the effect of iron intake on measures of cognitive development and function in infants, children and adolescents. Four systematic reviews on this topic have been published previously [14, 21-23]. However, they were limited to specific age ranges (e.g. young children or infants $<1$ year of age), considered only supplementation studies or focused on 
either anemic or nonanemic subjects. Our review aimed to answer the following questions: (1) what is the effect of iron intake on cognitive development and function?, and (2) what factors affect this relationship? Any source of iron was considered (diet, formula, supplements and fortified foods), and studies were assessed independently of the iron status of subjects at baseline.

\section{Methods}

This research is part of a project within the EURRECA network that aims to identify micronutrient requirements for optimal health in European populations (www.eurreca.org). The review reported here was part of a wider review process to identify studies assessing the effect of iron intake on different outcomes (markers of iron status and health outcomes). No review protocol was registered.

Search Methods for Identification of Studies

MEDLINE, Embase (both on Ovid) and the Cochrane Library CENTRAL database were searched up to and including February 2010. The search strategy included terms for '[study designs in humans] AND [intake or status] AND [iron]'. Both indexing and text terms were used. The search strategy was adapted for each of the individual databases. The search was not limited by language. The search strategy for MEDLINE is presented in Appendix 1. The reference lists of retrieved articles and published reviews were also checked for relevant studies.

Criteria for the Consideration of Studies for This Review

Studies had to fulfill the following criteria to be included in the review: (1) investigate how iron intake affect measures of cognitive development and function; (2) provide iron from supplements, fortified foods or natural dietary sources; (3) be RCTs with an adequate control (placebo or no intervention); (4) study infants, children or adolescents from birth to 18 years of age at the time of the intervention, and (5) include apparently healthy subjects.

Some studies included interventions with more than one micronutrient. When the effect of iron was not measured separately, the studies were not considered for review. Studies had to report baseline data for the measured outcomes to be included in the review. Studies on subjects with ID or IDA but otherwise healthy were included.

\section{Selection of Studies and Data Extraction}

Firstly, titles and abstracts were screened to exclude any references not meeting the inclusion criteria. Four independent reviewers were involved in data extraction. Two independent reviewers screened $10 \%$ of the references in duplicate. Any discrepancies at the duplicate screening step were discussed before screening the rest of the references. The rest of the references (90\%) were then divided among four reviewers who assessed if they were potentially relevant. The potentially relevant references were then located as full texts. All full texts were assessed twice for inclusion criteria by two independent reviewers. Disagreements were settled through discussion. Only papers reporting studies meeting all inclusion criteria were included in the review.
Data were then extracted into a standardized database, which included bibliographic details, methodological details, population characteristics, study group details and outcome data. Data from $30 \%$ of the total papers were extracted in duplicate. Any disagreements were discussed to achieve a uniform approach to data extraction. The remaining $70 \%$ of the papers was divided among four reviewers and extracted by a single reviewer.

Assessment of Risk of Bias in Included Studies

In order to assess the quality of the study and the risk of bias, the following indicators of internal validity were collected during data extraction. These indicators are specific to the RCT methodology: (1) method of sequence generation and allocation, (2) blinding, (3) potential funding bias, (4) number of participants at start, (5) dropouts and dropout reasons, (6) dose check (amount of iron provided), (7) dietary intake data reported, (8) outcome comparability and reproducibility, and (9) similarity at baseline of most and least exposed groups. Based on these indicators, two independent reviewers decided on the overall risk of bias. Disagreements were resolved by discussion. The criteria for judging these indicators were adapted from the Cochrane Handbook [24]. Additionally, we applied the Jadad score to assess the methodological quality of the studies [25]. This procedure scores the studies according to the presence of the three key methodological features of randomization, blinding and accountability of all patients, including withdrawals.

\section{Results}

Fourteen studies were eligible and were included in the review. Tables 1 and 2 show the key characteristics of the included studies on infants and young children, and on school-aged children and adolescents, respectively. Figure 1 shows the flow chart of the study selection process.

\section{Infants, Toddlers and Preschool Children}

Seven studies on infants and preschool children were included. Five of them were conducted on infants and toddlers 6-24 months of age. A supplementation trial in 24 nonanemic 6-month-old Turkish infants using doses of $1 \mathrm{mg} / \mathrm{kg} /$ day ferrous sulfate during 3 months showed no significant change in developmental test scores. The study used the Bayley Scales of Infant Development (BSID) Mental Development Index (MDI) scores and Psychomotor Development Index (PDI) scores [26].

One study in Indonesia included anemic and nonanemic infants up to 12 months of age. The infants were treated with ferrous sulfate $10 \mathrm{mg} /$ day alone, ferrous sulfate combined with zinc sulfate, zinc alone or placebo during 6 months. This study, which included a sample size of 680 subjects, indicated a small but significant positive effect of iron supplementation on motor development with single iron supplementation as assessed by the BSID (PDI score) 


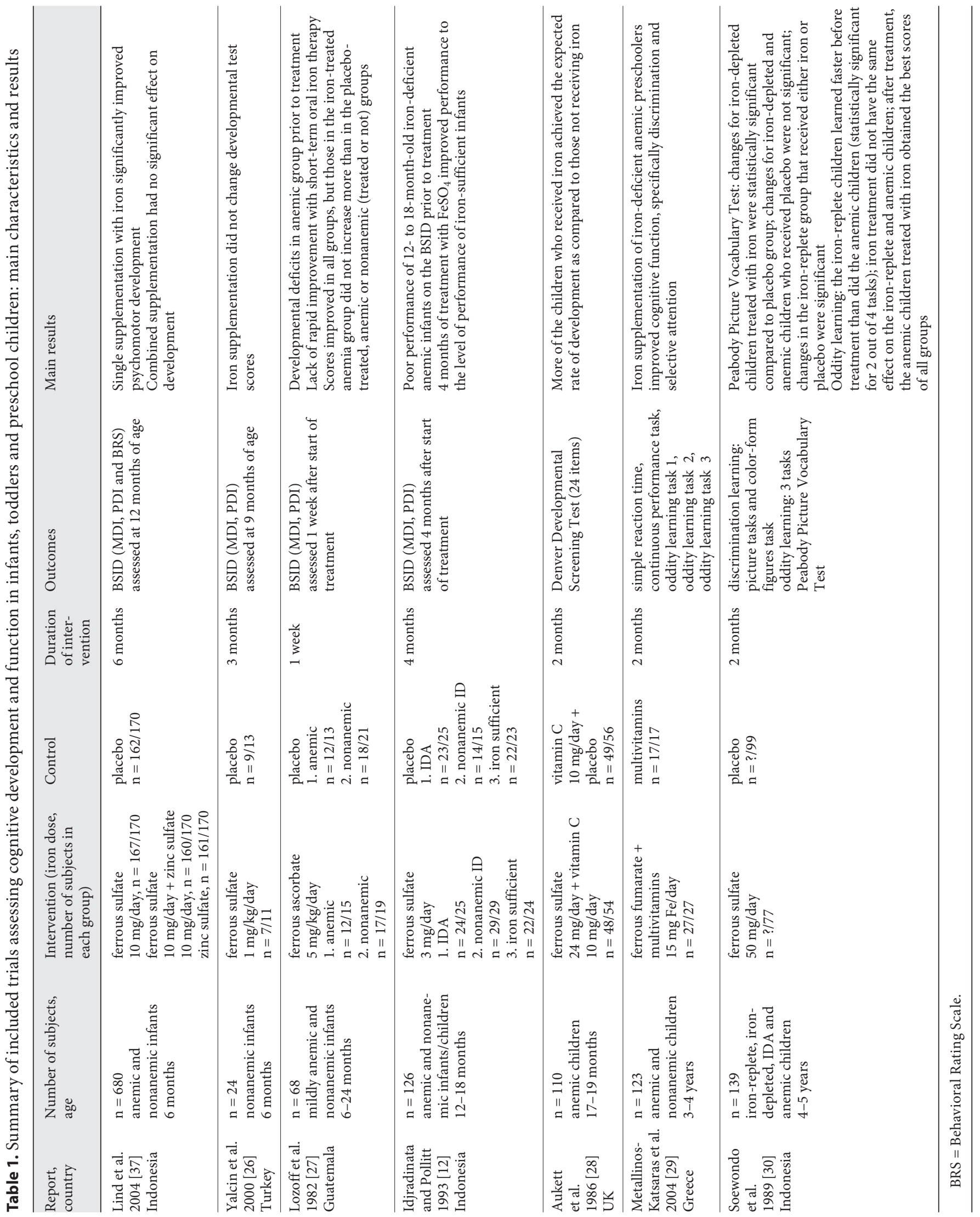




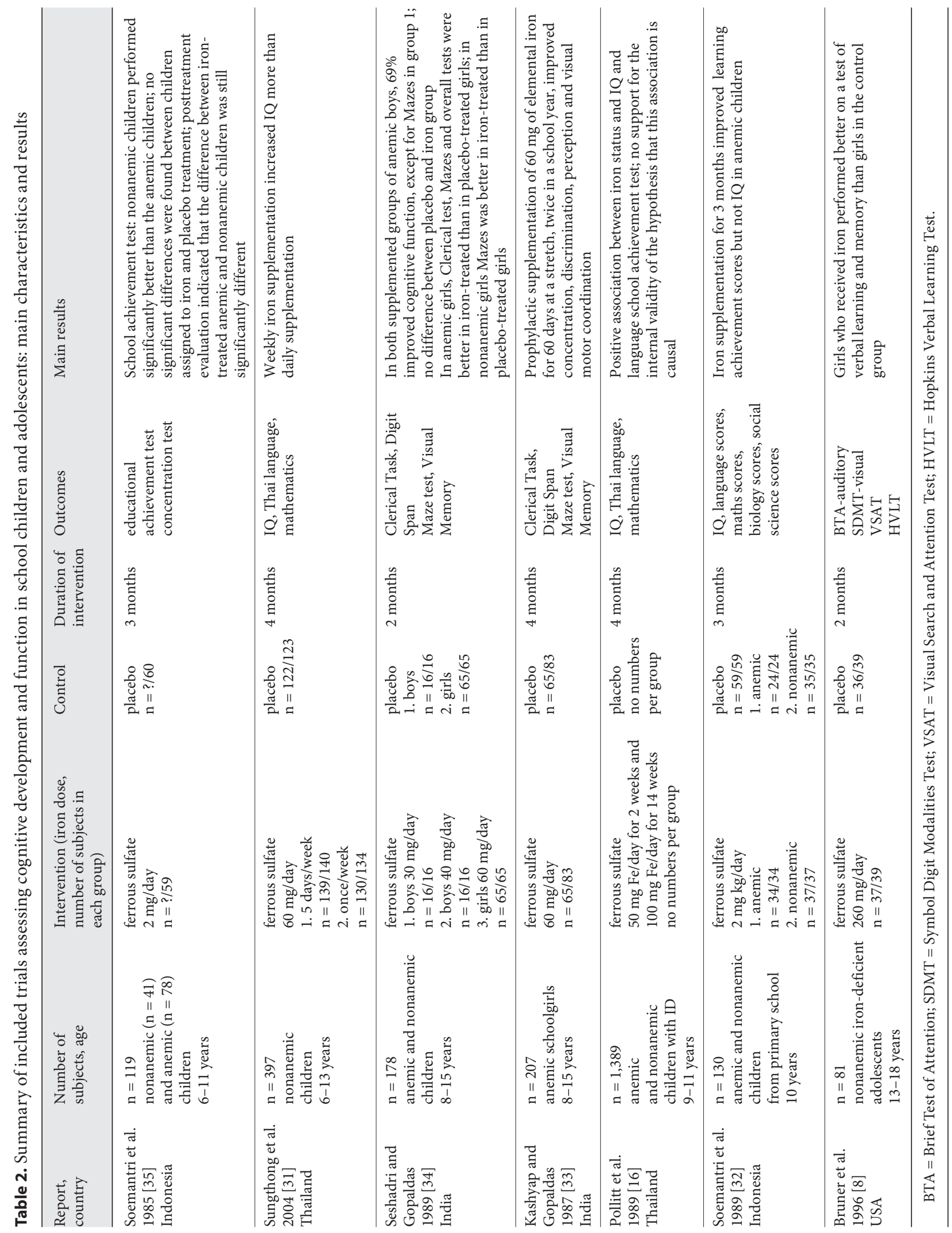


in all infants and in all groups. No significant effect was seen on cognitive development or behavior as assessed by the MDI score or Behavioral Rating Scale [23].

A trial in Guatemala that provided short-term iron supplementation for 1 week to 68 anemic and nonanemic infants and children up to 24 months of age found no benefit of the iron supplement when testing with the BSID. A dosage of ferrous ascorbate of $5 \mathrm{mg} / \mathrm{kg}$ was used [27].

A study by Idjradinata and Pollitt [12] in anemic and nonanemic 12 - to 18 -month-old children showed that iron treatment ( $3 \mathrm{mg} / \mathrm{kg} /$ day ferrous sulfate) during 4 months significantly improved BSID results in iron-deficient children. These even reached the performance level of iron-sufficient children, unlike the group treated with placebo $(\mathrm{p}<0.001)[12]$.

Two studies on anemic toddlers and young children in Europe (England and Greece) used outcomes other than BSID scales. Aukett et al. [28] used 24 items from the Denver Developmental Screening Test validated by the BSID in children 17-19 months old. In this treatment trial in a group of 110 anemic toddlers, $31 \%$ of them achieved 6 or more new skills after treatment with iron $(24 \mathrm{mg} /$ day ferrous sulfate combined with vitamin C) during 2 months, compared to $12 \%$ in the placebo plus vitamin Ctreated group $(p<0.05)$ [28]. Simple reaction time, continuous performance task and oddity learning tasks were used by Metallinos-Katsaras et al. [29]. Anemic children 3-4 years old made significantly fewer errors of commission $(14 \%$ higher specificity; p $<0.05)$ and exhibited $8 \%$ higher accuracy $(\mathrm{p}<0.05)$ after 2 months of iron treatment (15 mg of elemental iron daily, given as ferrous fumarate combined with multivitamins) than those given placebo (multivitamins without iron), suggesting improved discrimination and selective attention, although no effects were found on the oddity learning task. These positive effects of iron were not seen among the children with good iron status [29].

Soewondo et al. [30] applied a discrimination learning task, oddity learning task and the Peabody Picture Vocabulary Test in Indonesian children 4-5 years of age. They reported statistically significant positive changes for iron-depleted children treated with $50 \mathrm{mg} /$ day iron during 2 months compared to the placebo group when applying the Peabody Picture Vocabulary Test. No significant changes were seen for iron-depleted and anemic children, whereas changes in the iron-replete group were significant. When the oddity learning test was applied, the iron-replete children learned faster before treatment than did the anemic children (statistically significant for 2 out of 4 tasks). Iron treatment did not have the same ef- fect on the iron-replete and anemic children. After treatment, the anemic children treated with iron obtained the best scores of all groups [30].

\section{School Children and Adolescents}

The seven studies on school children and adolescents provided iron supplements in the form of ferrous sulfate $[8,16,31-35]$. Four studies included children and adolescents from 6 to 15 years of age [29-32], and 1 study included 13- to 18-year-old adolescents [8]. Two studies were performed on females only $[8,33]$.

One study was conducted in the USA [8], whereas the others were conducted in Asia: 2 in India [33, 34], 2 in Indonesia [32, 35] and 2 in Thailand [16, 31]. The dosages of supplemented iron varied widely. Doses between 2 and 60 $\mathrm{mg}$ of elemental iron daily in the form of ferrous sulfate were used in 5 studies (table 1). Bruner et al. [8] used markedly higher doses, i.e. $2 \times 2$ tablets of $325 \mathrm{mg}(1,300 \mathrm{mg}$ in total) of ferrous sulfate daily in adolescent girls, which is equivalent to $260 \mathrm{mg}$ of elemental iron daily. One of the studies conducted in Indonesia used a dose of iron that depended on the weight of the children, i.e. $2 \mathrm{mg} / \mathrm{kg} / \mathrm{day}$ [32], whereas the other Indonesian study provided iron doses of $2 \mathrm{mg} /$ day [35]. Pollitt et al. [16] increased the dose from 10 $\mathrm{mg} /$ day in the first 2 weeks to $20 \mathrm{mg} /$ day in the following 14 weeks. The duration of the interventions ranged from 2 to 4 months. In the 2 Indian studies, girls were treated for $2 \times 60$ days in a school year $[29,30]$. In most of the studies, children received the iron supplement daily during the intervention, except in the study by Sungthong et al. [31], in which children received $60 \mathrm{mg}$ of elemental iron 5 times per week or the same dose once a week. One study [33] was performed in anemic children, one study in NAID girls [8], one in apparently healthy children [31] and 5 studies in both anemic and nonanemic children [32, 34, 35], 2 of them including an NAID group [10, 14].

Two studies conducted in India used the same tests for assessment of cognitive function in children 8-15 years old, namely the Clerical Task test, Digit Span test, Mazes test and Visual Memory [33, 34]. Bruner et al. [8] used the Brief Test of Attention, Symbol Digit Modalities Test, Visual Search and Attention Test and Hopkins Verbal Learning Test. Soemantri et al. [35] measured educational achievement and tested concentration. In 3 studies, the authors measured IQ in children before and after iron intervention $[16,31,32]$. The large diversity of tests employed in the different studies hampered any quantitative comparison of results or meta-analysis.

In a study by Pollitt et al. [16], the IQ and scholastic achievement significantly increased in anemic children 
Table 3. Assessment of validity (adapted from the Cochrane Handbook) and of quality (Jadad scale) of included RCTs on effects of iron supply on measures of cognitive development and function

\begin{tabular}{|c|c|c|c|c|c|c|c|c|}
\hline Study & $\begin{array}{l}\text { Adequate } \\
\text { sequence } \\
\text { generation }\end{array}$ & $\begin{array}{l}\text { Allocation } \\
\text { concealment } \\
\text { adequate }\end{array}$ & $\begin{array}{l}\text { Blinding } \\
\text { adequate }\end{array}$ & $\begin{array}{l}\text { Dropouts adequate } \\
\text { and outcome } \\
\text { data complete }\end{array}$ & $\begin{array}{l}\text { Information } \\
\text { on funder } \\
\text { adequate }\end{array}$ & $\begin{array}{l}\text { Lack of other } \\
\text { potential threats } \\
\text { to validity }\end{array}$ & $\begin{array}{l}\text { Overall } \\
\text { risk } \\
\text { of bias [24] }\end{array}$ & $\begin{array}{l}\text { Jadad } \\
\text { score } \\
{[25]}\end{array}$ \\
\hline Aukett et al. 1986 [28] & unclear & yes & yes & yes & unclear & yes & high & 4 \\
\hline Bruner et al. $1996[8]$ & yes & yes & yes & yes & no & yes & moderate & 5 \\
\hline Idjradinata and Pollitt 1993 [12] & yes & yes & yes & yes & yes & yes & low & 5 \\
\hline Kashyap and Gopaldas 1987 [33] & unclear & unclear & unclear & no & yes & yes & high & 2 \\
\hline Lind et al. 2004 [37] & yes & yes & yes & yes & yes & unclear & low & 5 \\
\hline Lozoff et al. 1982 [27] & unclear & unclear & yes & yes & yes & unclear & high & 4 \\
\hline Metallinos-Katsaras et al. 2004 [29] & unclear & yes & yes & yes & no & yes & high & 4 \\
\hline Pollitt et al. $1989[16]$ & unclear & unclear & yes & unclear & yes & yes & high & 3 \\
\hline Seshadri and Gopaldas 1989 [34] & unclear & unclear & unclear & yes & unclear & yes & high & 2 \\
\hline Soemantri et al. 1985 [35] & unclear & unclear & unclear & unclear & yes & yes & high & 2 \\
\hline Soemantri et al. 1989 [32] & unclear & unclear & yes & yes & yes & yes & high & 4 \\
\hline Soewondo et al. 1989 [30] & unclear & unclear & yes & unclear & yes & yes & high & 3 \\
\hline Sungthong et al. 2004 [31] & yes & unclear & yes & yes & yes & yes & moderate & 4 \\
\hline Yalcin et al. 2000 [26] & unclear & unclear & no & yes & unclear & unclear & high & 3 \\
\hline
\end{tabular}

and to a lesser degree in NAID children 9-11 years old, after $10 \mathrm{mg} /$ day iron supplementation in the first 2 weeks and $20 \mathrm{mg} /$ day in the following 14 weeks.

Sungthong et al. [31] reported a significantly greater increase in IQ in 6- to 13-year-old children treated with $60 \mathrm{mg}$ of iron once weekly for 16 weeks ( $6 \pm 12$ points) or placebo ( $6 \pm 12$ points) than in children treated with the same dose of $60 \mathrm{mg}$ of iron 5 days a week $(3 \pm 12)$, while no difference in learning achievement was found among the groups.

No statistically significant improvement in IQ was found in an Indonesian study in children who received $2 \mathrm{mg} / \mathrm{kg} / \mathrm{day}$ iron for 3 months compared to the control group, but improved learning achievement scores were detected in anemic children treated with iron [32]. Another Indonesian study by the same authors providing $2 \mathrm{mg} / \mathrm{kg} /$ day iron for 3 months detected significantly better school achievement by nonanemic children compared to anemic children that persisted after treatment independently of iron or placebo treatment [35].

Sixty days of supplementation with 30 or $40 \mathrm{mg}$ of iron per day in 8- to 15 -year-old anemic boys induced a significant improvement in all cognitive functions compared to the placebo group ( $\mathrm{p}<0.05)$, except for the Mazes test in the $30 \mathrm{mg} /$ day group. No difference between the iron and placebo group was found in nonanemic boys [34]. Girls of the same age were treated for $2 \times$ 60 days with $60 \mathrm{mg} /$ day iron. Significantly better scores on the Clerical Task test, Digit Span test and Mazes test were reported after 8 months in the anemic girls treated with iron versus placebo $(\mathrm{p}<0.05)$, but not after 4 months [33]. Similar results were found by Seshadri and Gopaldas [34], but they also reported improved scores on the Mazes test in nonanemic girls after supplementation with iron. Higher doses of $260 \mathrm{mg} /$ day iron, given to NAID adolescent girls for 8 weeks, led to significantly better results on a test of verbal learning and memory when compared to girls in the placebo group $(\mathrm{p}<0.02)$ [8].

\section{Confounding Variables}

Many factors are associated with both IDA and cognitive function, including low socioeconomic status, poverty, poor quality of stimulation in the home, low levels of maternal education, maternal depression, low birth weight, early weaning, parasitic infection and undernutrition [36]. Some of these factors were present in most of the studies included in this review (e.g. low socioeconomic status, poverty, parasitic infection and undernutrition).

\section{Risk of Bias and Quality of the Studies Included}

Table 3 summarizes the internal validity of the included studies, assessed as described in the Methods section. The results show a high risk of bias in most of the studies. Only 2 studies $[12,37]$ had a low risk of bias. Two studies had a moderate risk of bias $[8,31]$. The main reasons for a high risk of bias were an unclear adequacy of sequence generation and/or allocation and inadequate information on funders. In most cases, insufficient in- 
Fig. 1. Flow diagram for the systematic review.

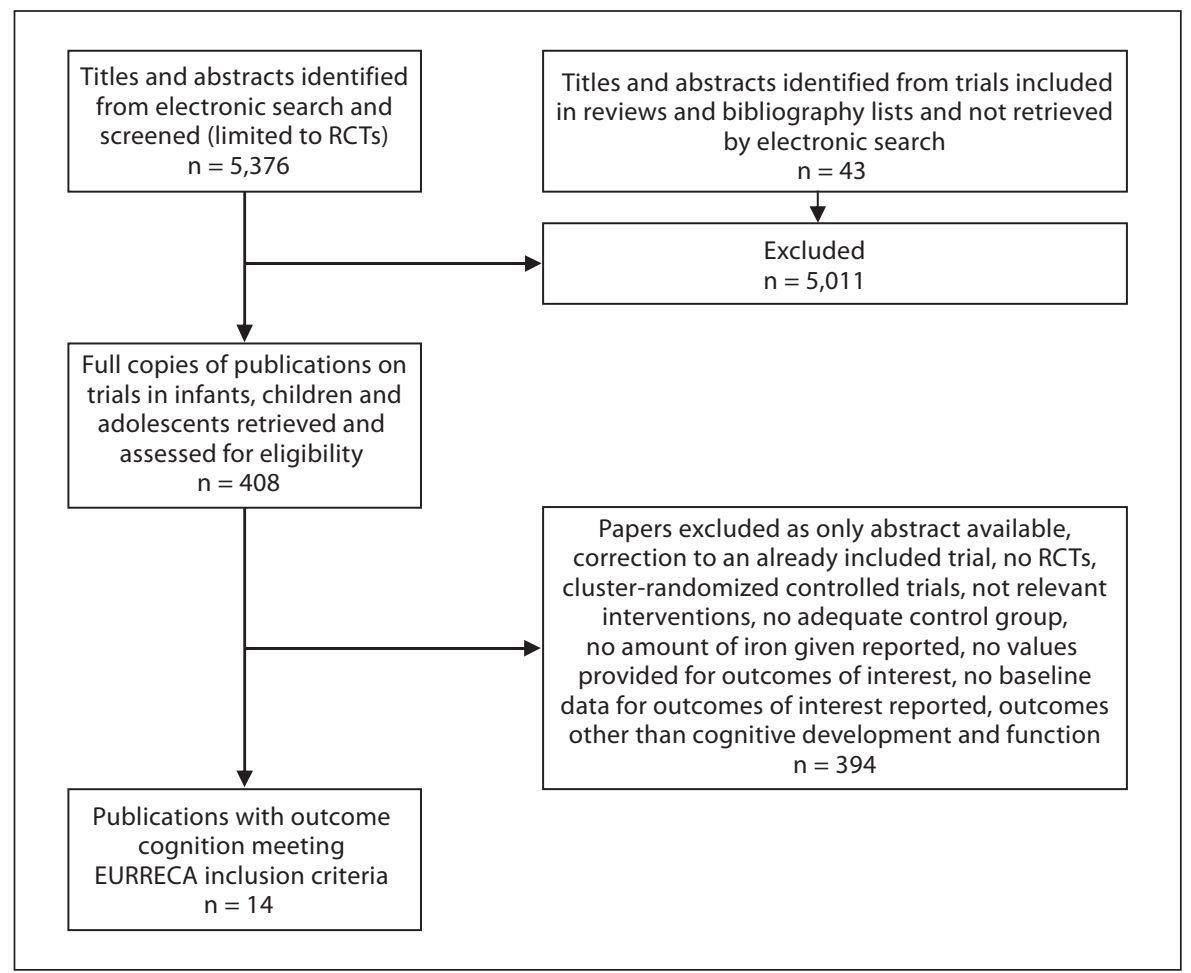

formation related to those criteria was given. When applying the Jadad score, 8 studies were classified as highquality studies (scores of 4 or 5) and 6 as low-quality studies (score $\leq 3$ ).

\section{Discussion}

\section{Evidence}

This review of 14 RCTs has assessed the effects of iron supplementation on measures of cognitive development and function in infants, children and adolescents. The overwhelming feature of this review is the limited number of relevant studies that could be identified and included in the review.

Only one study provided iron supplements for less than 2 months [27]. Based on this single study, there is no evidence of a positive effect of supplementation for 1 week on the mental and psychomotor development of anemic infants and children with and without IDA of 6-24 months of age.

For children aged 1-5 years, there is some evidence from 3 RCTs that iron supplementation during 2-4 months may have a positive effect on the mental and psychomotor development of anemic children [12, 28, 29].
Eight RCTs in anemic and nonanemic children over 5 years of age provided evidence for a positive effect of iron supplementation on different measures of cognition $[8$, $16,30-35]$. Due to the different parameters that were tested in the studies, it was very difficult to compare the studies and to achieve firm conclusions.

Given the data base available, it is not possible to derive clear evidence-based conclusions on the effect of iron supply on cognitive development and function in infants, children and adolescents. An important reason for this is that some of the trials originally had to be excluded because they did not have an adequate control group according to our criteria. Furthermore, the presence of other confounding variables, such as other nutritional deficiencies, low socioeconomic status and studies carried out in areas with endemic malaria, could have markedly influenced the results obtained.

Another remarkable limitation is the considerable heterogeneity of the study populations, which makes it difficult to compare and combine the available results. The heterogeneity of outcome measures precluded pooling study results quantitatively in a meta-analysis. The assessment of validity showed that most studies had a high risk of bias, independent of the methodological quality as assessed by the Jadad score. 


\section{Comparison with Other Systematic Reviews}

Unlike other systematic reviews on the topic, the present systematic review was not limited to supplementation studies. However, only supplementation trials complied with our inclusion criteria. Because we selected studies independently of the baseline iron status of participants, our systematic review covers trials on NAID and anemic iron-deficient subjects. In addition, our review includes studies performed in subjects across all age ranges from 0 to 18 years.

\section{Effect of Iron in Nonanemic Subjects}

A recent review with meta-analysis by Szajewska et al. [23] analyzed the effects of iron supplementation in nonanemic infants and young children on the mental performance and psychomotor development of children $(<3$ years). The 5 included RCTs did not individually show a beneficial effect of iron supplementation on the MDI of the BSID at different ages throughout the first 18 months. Three of the 5 RCTs showed a beneficial effect of iron supplementation on the PDI at some time points, whereas the other 2 did not. The authors performed 2 metaanalyses of 3 RCTs involving 561 infants and children. It was concluded that iron supplementation in infants may positively influence children's psychomotor development, whereas it does not seem to alter their mental development or behavior. Only 2 of the 5 RCTs on nonanemic infants included in this review were included in our review $[26,37]$. The other 3 were found by our search, but they were excluded because of lack of baseline data for the outcomes reported or because the exact quantity of iron supplied was not reported.

\section{Effect of Iron in Anemic and Nonanemic Subjects}

In 2005, Sachdev et al. [14] published a systematic review with a meta-analysis examining the effects of iron supplementation in relation to development in children. The review included 17 trials of oral iron supplementation, fortified milks and cereal and parenteral iron (all RCTs) involving 3,646 participants. The authors concluded that iron supplementation had modest but significant beneficial effects on mental development in children who were anemic or iron deficient at baseline and in all children $>7$ years old, particularly with regard to IQ scores. In younger children (aged $<27$ months), no effect of iron supplementation on mental development was detected. Motor development was not found to be improved through iron supplementation. Out of the 17 trials included in the review of Sachdev et al. [14], 6 were also included in our review. The rest were identified in the search but then excluded because the exact iron dose was not reported (1 study), the study was not randomized (2 studies), there was no control group (1 study), there was no adequate control group (1 study) and values for outcomes after supplementation were not reported (1 study).

A review by Iannotti et al. [38] on the benefits and risks of iron supplementation of infants and children under 5 years of age in developing countries published in 2006 concluded that providing additional iron via daily or weekly supplementation to preschool iron-deficient children may have had some positive effects on developmental indicators, especially among children who were anemic or iron deficient at baseline. Eight studies were included in this review for the outcome 'development'. Four of them were also included in our review. Those not included in our review did not report the amount of iron given to the study participants (1 study), the results were reported in such a way that we could not compare groups (1 study), the necessary values were not reported (1 study) or there was no control group for the outcome of interest (1 study).

A Cochrane review by Martins et al. [22] aimed to assess the effects of iron supplementation of iron-deficient infants and children under 3 years of age, beginning supplementation before 1 year of age, on measures of psychomotor development or cognitive function. Seven RCTs providing oral or intramuscular iron were included in this review, 5 of which assessed psychomotor development between 5 and 11 days of commencement of therapy. It was concluded that there was no convincing evidence that administration of iron improved scores on tests of psychomotor development within 6-11 days of treatment. The effect of longer interventions unfortunately remained unclear from the results of the other 2 studies, which assessed outcomes more than 30 days after commencing iron supplementation. Three studies included in this review were also included in our review. From those not included in our review, 1 was an unpublished study, 1 was excluded because the relevant values were not reported, 1 was cluster-randomized, 1 did not report the amount of iron supplied to study participants and another did not have an adequate control group for the outcomes of interest.

Falkingham et al. [21] recently published a systematic review assessing the effects of iron supplementation on cognition in older children ( $>6$ years) and adults. They included 14 RCTs and concluded that iron supplementation improved attention and concentration in all studies irrespective of baseline iron status. In anemic groups of children, supplementation improved IQ but had no effect on nonanemic participants. No effect of iron supplemen- 
tation on memory, psychomotor skills or scholastic achievement was found. However, the authors emphasized the limited number of studies included, which were generally conducted in small samples of subjects, had a short duration and were methodologically weak. Ten of the studies included in the review of Falkingham et al. [21] were performed in children 6-18 years old. Five of them were not included in our review because of the following reasons: (1) 3 of the studies had no adequate control group according to our criteria, (2) 1 study had a leadexposed population (3) and in 1 study no baseline data were reported.

\section{Limitations of This Review}

Four out of 7 studies on cognitive function in school children and adolescents included in this review had a supplementation period shorter than 12 weeks (tables 1 , 2 ), which is considered hardly sufficient to alter the iron status [21]. This could have possibly negated the effects of iron supplementation. However, these studies showed similar effects on cognition compared to studies with longer supplementation periods. Additionally, a 3-monthlong study [32] showed no effects of supplementation on IQ in anemic (and nonanemic) children, which the authors explained by several factors such as mucosal block or other unidentified causes that were not detected during the study (e.g. genetic factors that control absorption). Although a much longer duration of intervention is probably needed for outcomes such as scholastic achievement, where iron status during learning may be different from iron status at assessment of performance [21], they found improved learning results after iron supplementation.

An important limitation of this review is the high risk of bias of most of the included papers. In most papers, the sequence generation and/or allocation were not well addressed according to our criteria or they were not clearly reported. Funders were judged inadequate or information on funders was not reported in 4 studies on cognition (table 3). Only 2 studies were assessed as having a low risk of bias.

Development is often evaluated in a similar way in infants and young children (e.g. BSID). In older children, different tests were used to assess developmental outcomes. Thus, comparison between studies was more difficult. In addition, different iron status at baseline (anemic, nonanemic and NAID subjects) and varying socioeconomic status of the participants make the assessment of the effects of iron interventions on cognitive functions difficult. The effects of iron might be rather different depending on the baseline iron status.
The reviewers tried to identify ongoing studies that could potentially be considered for inclusion in the review. This was done by contacting experts in the field. No other means were applied to find unpublished research, and so only published studies were included in the review. Thus, the review could be subject to publication bias because some unpublished studies may have been missed.

\section{Recommendations for Practice and Research}

Until more convincing evidence exists that iron supplementation can significantly improve measures of cognitive function and development in infants, children and adolescents, policy should focus on prevention of IDA.

RCTs in infants, children and adolescents should be conducted in a way that facilitates comparison with other studies and meta-analysis. Reporting studies in a standardized way would also contribute to a more evidencebased nutrition. The Consolidated Standards of Reporting Trials statement [39] should improve the reporting of RCTs.

\section{Acknowledgments}

The original conception of this systematic review was developed by the EURRECA Network and coordinated by partners based at Wageningen University (WU), The Netherlands, and the University of East Anglia (UEA), United Kingdom. Susan Fairweather-Tait (UEA), Lisette de Groot (WU), Pieter van' t Veer (WU), Kate Ashton (UEA), Amélie Casgrain (UEA), Adriënne Cavelaars (WU), Rachel Collings (UEA), Rosalie DhonuksheRutten (WU), Esmée Doets (WU), Linda Harvey (UEA) and Lee Hooper (UEA) designed and developed the review protocol and search strategy. The authors are grateful to all EURRECA members and partners involved in database searching, screening and data entry for iron: Rachel Collings (UEA), Amelie Casgrain (UEA) and Joy Ngo (Community Nutrition Research Centre of the Nutrition Research Foundation, Barcelona, Spain, FIN).

\section{Disclosure Statement}

The work reported herein was carried out within the EURRECA Network of Excellence (http://www.eurreca.org), which is financially supported by the Commission of the European Communities' specific Research Technology and Development Programme Quality of Life and Management of Living Resources, within the Sixth Framework Programme (contract No. 036196). This report does not necessarily reflect the Commission's views or its future policy in this area. B.K. is the recipient of a Freedom to Discover Award of the Bristol Myers Squibb Foundation, New York, N.Y., USA.

The authors declare no conflict of interest. 


\section{Appendix}

Search strategy: MEDLINE February 2009 and February 2010

\begin{tabular}{|c|c|c|c|}
\hline $\begin{array}{l}\text { Search } \\
\text { No. }\end{array}$ & Search & Results & $\begin{array}{l}\text { Search } \\
\text { type }\end{array}$ \\
\hline 1 & randomized controlled trial. pt. & 261,515 & advanced \\
\hline 2 & controlled clinical trial. pt. & 77,893 & advanced \\
\hline 3 & randomized. ab. & 172,980 & advanced \\
\hline 4 & clinical trials as topic.sh. & 140,006 & advanced \\
\hline 5 & randomly. ab. & 125,849 & advanced \\
\hline 6 & randomized. ab. & 33,552 & advanced \\
\hline 7 & (animals not (human and animals)). sh. & $4,293,014$ & advanced \\
\hline 8 & $\begin{array}{l}\left.\text { ((iron or ferric or ferrous or ferr }{ }^{*}\right) \text { adj3 (intake* or diet* or supplement* or deplet* or status or } \\
\left.\text { expos* }^{*} \text { or concentration* }\right) \text { ). ti, ab. }\end{array}$ & 14,306 & advanced \\
\hline 9 & (hemoglobin* or haemoglobin*). ti, ab. & 84,956 & advanced \\
\hline 10 & $\begin{array}{l}\text { ((serum adj3 ferritin) or (plasma adj3 ferritin) or (serum adj3 apoferritin) or } \\
\text { (plasma adj3 apoferritin) or (serum adj3 'transferrin receptor*') or } \\
\left.\text { (plasma adj3 'transferrin receptor*') or (serum adj3 } \mathrm{TFR}^{*} \text { ) or (plasma adj3 TFR }{ }^{*}\right) \text { ). ti, ab. }\end{array}$ & 6,042 & advanced \\
\hline 11 & *iron, dietary/ & 806 & advanced \\
\hline 12 & (iron or ferrous or ferric or ferr*). ti, ab. & 116,185 & advanced \\
\hline 13 & (intake* or diet* or fortif* or supplement* or deplet* ${ }^{*}$ or status or concentration* or expos*).ti,ab. & $2,148,582$ & advanced \\
\hline 14 & $\begin{array}{l}\text { nutritional support/ or dietary supplements/ or nutritional requirements/ or } \\
\text { exp nutritional status/ or exp deficiency diseases/ or supplementation/ }\end{array}$ & 108,850 & advanced \\
\hline 15 & $\begin{array}{l}\text { diet supplementation/ or dietary intake/ or exp diet restriction/ or exp mineral intake/ or diet/ or } \\
\text { food, fortified/ or nutrition assessment/ or nutritive value/ }\end{array}$ & 94,854 & advanced \\
\hline 16 & 6 or 4 or 1 or 3 or 2 or 5 & 578,036 & advanced \\
\hline 17 & 16 not 7 & 516,057 & advanced \\
\hline 18 & 10 or 9 & 89,036 & advanced \\
\hline 19 & 13 or 15 or 14 & $2,231,529$ & advanced \\
\hline 20 & 11 or 12 & 116,199 & advanced \\
\hline 21 & 18 or 19 & $2,289,421$ & advanced \\
\hline$\overline{22}$ & 21 and 20 & 46,409 & advanced \\
\hline 23 & 22 or 8 & 46,409 & advanced \\
\hline 24 & 23 and 17 & 2,311 & advanced \\
\hline 25 & breast feeding/ or exp infant food/ & 26,392 & advanced \\
\hline 26 & bottle feeding/ & 2,725 & advanced \\
\hline 27 & 25 or 26 & 27,172 & advanced \\
\hline 28 & infant formula/ & 1,023 & advanced \\
\hline 29 & 27 or 28 & 27,172 & advanced \\
\hline 30 & 19 or 29 & $2,248,563$ & advanced \\
\hline 31 & 18 or 30 & $2,306,432$ & advanced \\
\hline 32 & 8 or 31 & $2,306,432$ & advanced \\
\hline 33 & 32 and 20 & 46,494 & advanced \\
\hline 34 & 33 and 17 & 2,321 & advanced \\
\hline
\end{tabular}

$\mathrm{pt}=$ Publication type $\mathrm{ab}=$ abstract; $\mathrm{sh}=$ subject heading; adj3 = adjacency (terms in any order with three words (or fewer) between them); ti = title. 


\section{References}

1 Institute of Medicine: Dietary Reference Intakes for Vitamin A, Vitamin K, Arsenic, Boron, Chromium, Copper, Iodine, Iron, Manganese, Molybdenum, Nickel, Silicon, Vanadium, and Zinc. Washington, National Academy Press, 2000.

$\checkmark 2$ Leung AK, Chan KW: Iron deficiency anemia. Adv Pediatr 2001;48:385-408.

-3 Thane CW, Bates CJ, Prentice A: Risk factors for low iron intake and poor iron status in a national sample of British young people aged 4-18 years. Public Health Nutr 2003;6:485496.

-4 Iglesia I, Doets EL, Bel-Serrat S, Román B, Hermoso M, Peña Quintana L, García-Luzardo MdR, Santana-Salguero B, GarcíaSantos Y, Vucic V, Frost Andersen L, PérezRodrigo C, Aranceta J, Cavelaars A, Decsi T, Serra-Majem L, Gurinovic M, Cetin I, Koletzko B, Moreno LA: Physiological and public health basis for assessing micronutrient requirements in children and adolescents. The EURRECA network. Matern Child Nutr 2010;6:84-99.

5 Clark SF: Iron deficiency anemia. Nutr Clin Pract 2008;23:128-141.

-6 Ferrara M, Coppola L, Coppola A, Capozzi L: Iron deficiency in childhood and adolescence: retrospective review. Hematology 2006;11:183-186

7 Gibson RS, Heath AL, Ferguson EL: Risk of suboptimal iron and zinc nutriture among adolescent girls in Australia and New Zealand: causes, consequences, and solutions. Asia Pac J Clin Nutr 2002;11(suppl 3):S543S552.

$\checkmark 8$ Bruner AB, Joffe A, Duggan AK, Casella JF, Brandt J: Randomised study of cognitive effects of iron supplementation in non-anaemic iron-deficient adolescent girls. Lancet 1996;348:992-996.

9 World Health Organization: Infant and young child nutrition. WHO 55th Assembly (WHA55.25, agenda item 13.10), 2002.

10 World Health Organization: Iron deficiency anaemia: assessment, prevention, and control. A guide for programme managers. Geneva, WHO, 2001.

11 Allen L, de Benoist B, Dary O, Hurrell R (eds): Guidelines on food fortification with micronutrients. Geneva, World Health Organization, Food and Agricultural Organization of the United Nations, 2006.

12 Idjradinata P, Pollitt E: Reversal of developmental delays in iron-deficient anaemic infants treated with iron. Lancet 1993;341:1-4.

13 Scientific Committee on Food of the European Commission: Report of the scientific committee on food on the revision of essential requirements of infant formulae and follow-on formulae. Brussels, Scientific Committee on Food, European Commission, 2003.
14 Sachdev H, Gera T, Nestel P: Effect of iron supplementation on mental and motor development in children: systematic review of randomised controlled trials. Public Health Nutr 2005;8:117-132.

15 Grantham-McGregor S, Ani C: A review of studies on the effect of iron deficiency on cognitive development in children. J Nutr 2001;131:649S-666S, discussion 666S-668S.

16 Pollitt E, Hathirat P, Kotchabhakdi NJ, Missell L, Valyasevi A: Iron deficiency and educational achievement in Thailand. Am J Clin Nutr 1989;50:687-696, discussion 696-687.

17 Benton D: Micronutrient status, cognition and behavioral problems in childhood. Eur J Nutr 2008;47:38-50.

18 Lozoff B, Georgieff MK: Iron deficiency and brain development. Semin Pediatr Neurol 2006;13:158-165.

19 Beard JL: Why iron deficiency is important in infant development. J Nutr 2008; 138 : 2534-2536.

20 Ashwell M, Lambert JP, Alles MS, Branca F, Bucchini L, Brzozowska A, de Groot LC, Dhonukshe-Rutten RA, Dwyer JT, Fairweather-Tait S, Koletzko B, Pavlovic M, Raats MM, Serra-Majem L, Smith R, van Ommen B, Veer P, von Rosen J, Pijls LT: How we will produce the evidence-based EURRECA toolkit to support nutrition and food policy. Eur J Nutr 2008;47(suppl 1):2-16.

21 Falkingham M, Abdelhamid A, Curtis P, Fairweather-Tait S, Dye L, Hooper L: The effects of oral iron supplementation on cognition in older children and adults: a systematic review and meta-analysis. Nutr J 2010;9: 4-19.

22 Martins S, Logan S, Gilbert RE: Iron therapy for improving psychomotor development and cognitive function in children under the age of three with iron deficiency anaemia. Cochrane Database Syst Rev 2001;(2): CD001444s.

23 Szajewska H, Ruszczynski M, Chmielewska A: Effects of iron supplementation in nonanemic pregnant women, infants, and young children on the mental performance and psychomotor development of children: a systematic review of randomized controlled trials. Am J Clin Nutr 2010;91:1684-1690.

24 Higgins JPT, Green S (eds): Cochrane Handbook for Systematic Reviews of Interventions, version 5.0.2 (updated September 2009). The Cochrane Collection, 2009.

25 Jadad AR, Moore RA, Carroll D, Jenkinson C, Reynolds DJ, Gavaghan DJ, McQuay HJ: Assessing the quality of reports of randomized clinical trials: is blinding necessary? Control Clin Trials 1996;17:1-12.
26 Yalcin SS, Yurdakok K, Acikgoz D, Ozmert E: Short-term developmental outcome of iron prophylaxis in infants. Pediatr Int 2000; 42:625-630.

27 Lozoff B, Brittenham GM, Viteri FE, Wolf AW, Urrutia JJ: The effects of short-term oral iron therapy on developmental deficits in iron-deficient anemic infants. J Pediatr 1982; 100:351-357.

28 Aukett MA, Parks YA, Scott PH, Wharton BA: Treatment with iron increases weight gain and psychomotor development. Arch Dis Child 1986;61:849-857.

29 Metallinos-Katsaras E, Valassi-Adam E, Dewey KG, Lonnerdal B, Stamoulakatou A, Pollitt E: Effect of iron supplementation on cognition in Greek preschoolers. Eur J Clin Nutr 2004;58:1532-1542.

30 Soewondo S, Husaini M, Pollitt E: Effects of iron deficiency on attention and learning processes in preschool children: Bandung, Indonesia. Am J Clin Nutr 1989;50:667-673, discussion 673-664.

- 31 Sungthong R, Mo-Suwan L, Chongsuvivatwong V, Geater AF: Once-weekly and 5-days a week iron supplementation differentially affect cognitive function but not school performance in Thai children. J Nutr 2004;134: 2349-2354

- 32 Soemantri AG, Gopaldas T, Seshadri S, Pollitt E: Preliminary findings on iron supplementation and learning achievement of rural Indonesian children. Am J Clin Nutr 1989; 50:698-702.

33 Kashyap P, Gopaldas T: Impact of hematinic supplementation on cognitive function in underprivileged school girls (8-15 yrs of age). Nutr Res 1987;7:1117-1126.

34 Seshadri S, Gopaldas T: Impact of iron supplementation on cognitive functions in preschool and school-aged children: the Indian experience. Am J Clin Nutr 1989;50:675684, discussion 685-676

35 Soemantri AG, Pollitt E, Kim I: Iron deficiency anemia and educational achievement. Am J Clin Nutr 1985;42:1221-1228.

36 Scientific Advisory Committee on Nutrition: Iron and Health. London, TSO, 2010.

37 Lind T, Lonnerdal B, Stenlund H, Gamayanti IL, Ismail D, Seswandhana R, Persson L-A: A community-based randomized controlled trial of iron and zinc supplementation in Indonesian infants: effects on growth and development. Am J Clin Nutr 2004;80:729736.

38 Iannotti LL, Tielsch JM, Black MM, Black RE: Iron supplementation in early childhood: health benefits and risks. Am J Clin Nutr 2006;84:1261-1276

39 Schulz KF, Altman DG, Moher D: CONSORT 2010 statement: updated guidelines for reporting parallel group randomised trials. BMJ 2010;340:c332. 